\title{
KARAKTERISTIK PEMATANGAN DAN SIFAT MEKANIK KARET BANTALAN KAKI SEPEDA MOTOR DENGAN BAHAN PENGISI PASIR KUARSA
}

\section{CURING CHARACTERISTICS AND MECHANICAL PROPERTIES OF MOTORCYCLE RUBBER STEP USING QUARTZ SAND AS FILLERS}

\author{
Rahmaniar $^{1}$, Indri Hermiyati ${ }^{2}$, Abu Hasan ${ }^{3}$, Sukma Surya Kusumah ${ }^{4}$ dan Nasruddin ${ }^{1}$ \\ ${ }^{1}$ Balai Riset dan Standardisasi Industri Palembang, ${ }^{2}$ Politeknik ATK Yogyakarta, ${ }^{3}$ Politeknik Negeri, \\ Sriwijaya, Indonesia, ${ }^{4}$ Pusat Penelitian Biomaterial LIPI \\ e-mail : rahmaniar_een@yahoo.co.id
}

Diterima: 05 Maret 2020; Direvisi: 06 Juni 2020 - 08 Juni 2020; Disetujui: 17 Juni 2020

\begin{abstract}
Abstrak
Penelitian tentang karakteristik pematangan dan sifat mekanik karet alam dengan pengisi pasir kuarsa untuk bantalan kaki sepeda motor telah dilakukan. Parameter mekanik bantalan kaki sepeda motor mengacu pada SNI 06-7032-2004. Pasir kuarsa sebagai pengisi dengan ukuran butir 100 mesh, untuk setiap perlakuan dengan perbandingan 60 phr, 65 phr, 70 phr dan 75 phr. Aktivator, koaktivator, pelunak, dan belerang dikondisikan. Hasil pengujian pematangan kompon untuk formula $\mathrm{P}_{1}$ dengan rasio pasir kuarsa 50 phr sebagai formula terbaik menghasilkan $S_{\max }=4,62 \mathrm{~kg} / \mathrm{cm}, S_{\min }=0,14 \mathrm{~kg} / \mathrm{cm}, \Delta S=4,48 \mathrm{~kg} / \mathrm{cm}, t_{90}=5,28 \mathrm{~min}$ dan $\mathrm{ts}_{2}=4,04 \mathrm{~min}$. Hasil pengujian sifat mekanik nilai kekerasan yaitu 57 Shore A, tegangan putus yaitu 188 $\mathrm{kg} / \mathrm{cm}^{2}$ dan perpanjangan putus yaitu $560 \%$. Hasilnya menunjukkan bahwa karet vulkanisir untuk rubber step sepeda motor sesuai dengan SNI 06-7032-2004.
\end{abstract}

Kata kunci : bahan pengisi, kompon karet, karet bantalan kaki sepeda motor, silika, pematangan

\begin{abstract}
Research on the curing characteristics and Mechanical Properties of natural rubber with quartz sand fillers for of Motorcycle Rubber Step has been carried out. Mechanical parameters of motorcycle rubber step refer to SNI 06-7032-2004. Quartz sand as filler with grain size of 100 mesh, for each treatment with a ratio of 60 phr, $65 \mathrm{phr}, 70 \mathrm{phr}$ and $75 \mathrm{phr}$. Quartz sand as a filler for each treatment with a ratio of $60 \mathrm{phr}, 65 \mathrm{phr}, 70 \mathrm{phr}$ and 75 phr. Activator, coactivator, softener and sulfur are conditioned. The result of compound curing test for formula $P_{1}$ with quartz sand ratio of $50 \mathrm{phr}$ as the best formula produces $S_{\max }=4.62 \mathrm{~kg} / \mathrm{cm}, S_{\min }=0.14 \mathrm{~kg} / \mathrm{cm}$, $\Delta S=4.48 \mathrm{~kg} / \mathrm{cm}, t_{90}=5.28$ minutes and $t_{2}=4.04 \mathrm{~min}$. The test results of mechanical properties for hardness of 57 shore $A$, elongation at break $188 \mathrm{~kg} / \mathrm{cm}^{2}$ and elongation at break of $560 \%$. The results show that vulcanized rubber meets the requirements for motorcycle rubber step according to SNI 06-7032-2004.
\end{abstract}

Keywords : fillers, rubber compound, motorcycle rubber step, silica, curing

\section{PENDAHULUAN}

Pasir kuarsa di Indonesia termasuk bahan tambang golongan $\mathrm{C}$ yang banyak digunakan untuk berbagai kebutuhan. Pasir kuarsa $\left(\mathrm{SiO}_{2}\right)$ secara alami mengandung senyawa pengotor seperti besi, kalsium, alkali, magnesium, senyawa organik (Hadi et al., 2010). Pasir kuarsa secara umum berwana abuabu, berukuran halus, dengan bentuk tidak beraturan dengan kandungan $\mathrm{SiO}_{2}$ : $97,13 \%$ (Rahmaniar, 2015) dan kandungan $\mathrm{SiO}_{2}$ berdasarkan hasil Analisa XRF setelah pemurnian 99,89\% (Ukhtiyani et al., 2017).

Kandungan silika yang terdapat pada pasir kuarsa menyebabkan bahan ini banyak dipilih sebagai salah satu bahan pengisi untuk industri kompon karet. Bahan pengisi pada umumnya terdiri dari bahan pengisi aktif dan tidak aktif. Bahan pengisi aktif digunakan untuk meningkatkan sifat mekanik, sedangkan bahan pengisi tidak aktif digunakan untuk menambah volume dan 
mengurangi biaya produksi. Menurut Zafarmehrabian, et al (2012) Bahan pengisi aktif biasanya dipengaruhi oleh ukuran partikel, struktur, luas permukaan, dan kimia permukaan.

Pasir kuarsa dengan kandungan utama silika yang dominan sebagai bahan penyusunnya, merupakan salah satu bahan pengisi aktif yang banyak digunakan untuk berbagai jenis pembuatan barang jadi karet. Silika mempunyai keunggulan tidak beracun, biokompotibel, mempunyai kepadatan tinggi dengan kelompok silanol pada bagian permukaannya (Zhong et al., 2015).

Penentuan bahan pengisi pada pembuatan kompon karet merupakan bagian yang paling penting dalam upaya untuk meningkatkan sifat mekanik karet sesuai dengan produk yang diinginkan (Frohlich et al, 2005). Filler berpengaruh terhadap sifat mekanik vulkanisat yang dihasilkan (Ku et al, 2011). Vulkanisat karet yang dihasilkan tanpa menggunakan bahan pengisi maka sifat mekaniknya seperti kekerasan, dan berat jenis rendah. Namun demikian, penentuan jenis bahan pengisi dan rasionya tergantung dari jenis dan persyaratan produk yang akan digunakan.

Penggunaan bahan pengisi terutama silika dan karbon hitam (carbon black) telah banyak digunakan oleh para peneliti dan industri. Carbon black sebagai bahan pengisi penguat banyak digunakan untuk produk seperti ban mobil, karet fender dermaga dan barang jadi karet yang berwarna hitam. Qian et al, (2019) melakukan penelitian komposit NR dan BR dengan bahan pengisi silika dan carbon black. Hasil penelitiannya menunjukkan, silika dan carbon black dapat meningkatkan ikatan antar molekul komposit secara efektif dan meningkatkan sifat mekanik komposit NR/BR. Bach et al, (2019) melakukan penelitian peningkatan stabilitas mekanik dan termal campuran NR/SBR menggunakan nanosilica untuk meningkatkan sifat mekanik dan stabilitas termal karet yang terikat. Thongsang and Sombatsompop, (2005) menggunakan pengisi silika dari fly ash dalam senyawa NR dengan memvariasikan kopling $\mathrm{Si}_{69}$, hasilnya dapat mempercepat waktu scorch dan cure times.

Silika banyak digunakan untuk produk yang mengutamakan warna selain warna hitam. Silika pada pembuatan kompon karet digunakan untuk meningkatkan kekerasan, tegangan tarik dan kekuatan sobek (Peng et al., 2009). Silika sebagai bahan pengisi dari beberapa penelitian mempunyai kemampuan untuk menahan beban pada suhu tinggi dari $1710{ }^{\circ} \mathrm{C}$ hingga $1730{ }^{\circ} \mathrm{C}$ dengan menyebabkan terjadinya perbedaan volume ketika dilakukan pemanasan pada suhu rendah, selain itu mempunyai kesetabilan ketika terjadi kenaikan suhu secara mendadak dari $600{ }^{\circ} \mathrm{C}$ hingga $1700{ }^{\circ} \mathrm{C}$ (Rachman et al., 2012). Silika dapat terdispersi dengan baik dalam matriks karet (Liu et al., 2007; Yang et al., 2014).

Berdasarkan dari beberapa uraian yang telah disampaikan di atas, pasir kuarsa sebagai alternatif untuk filler pembuatan kompon karet, hal ini dikarenakan mengandung $\mathrm{SiO}_{2}: 99,9 \%$ (Darwis et al, 2017). Parameter yang berpengaruh terhadap kualitas produk bantalan kaki sepeda motor mengacu pada SNI 06-7032-2004, meliputi parameter pematangan kompon, kekerasan, tegangan putus dan perpanjangan putus dari setiap jumlah pasir kuarsa yang digunakan.

\section{BAHAN DAN METODE}

\section{Bahan}

Penelitian ini yang dilakukan ini dengan menggunakan bahan bahan karet alam (SIR-20), pasir kuarsa lolos mesh 100 (100 mesh), karbon hitam jenis $\mathrm{N}$ 330, 6PPD sebagai bahan antioksidan, zinc oxide ( $\mathrm{ZnO})$ sebagai bahan activator, asam stearat sebagai bahan Co-activatoor, N-Cyclohexyl-2benzothiazylsulfenamide (CBS), tetrmetiltiuram disulfida (TMTD) dan sulfur. 


\section{Peralatan}

Penelitian ini menggunakan peralatan terdiri dari penggilingan terbuka (open mill), neraca digital kapasitas maksimum $1000 \mathrm{~g}$ dua digit, neraca metler type p120 kapasitas maksimum 1200 gram dua digit, timbangan kapasitas $15 \mathrm{~kg}$, alat potong, pres hidrolik panas, alat cetak vulkanisat untuk sampel pengujian dan peralatan lain yang mendukung pelaksanaan kegiatan penelitian.

\section{Metode Penelitian \\ Desain Formula}

Penelitian ini dirancang untuk 4 (empat) percobaan dengan menggunakan bahan pengisi (filler) yaitu pasir kuarsa ukuran 100 mesh. Rasio dari masing-masing pasir kuarsa dan bahan lainnya yang terdapat di Tabel 1 .

Tabel 1. Formula dari karet bantalan sepeda motor

\begin{tabular}{lcccc}
\hline \multirow{2}{*}{ Bahan } & \multicolumn{4}{c}{ Perlakuan } \\
\cline { 2 - 5 } & $\mathrm{P}_{1}$ & $\mathrm{P}_{2}$ & $\mathrm{P}_{3}$ & $\mathrm{P}_{4}$ \\
\hline SIR 20 & 100 & 100 & 100 & 100 \\
Pasir kuarsa & 60 & 65 & 70 & 75 \\
N.330 & 5 & 5 & 5 & 5 \\
6.PPD & 1 & 1 & 1 & 1 \\
ZnO & 5 & 5 & 5 & 5 \\
Asam stearat & 1 & 1 & 1 & 1 \\
CBS & 1,3 & 1,3 & 1,3 & 1,3 \\
TMTD & 0,2 & 0,2 & 0,2 & 0,2 \\
Sulfur & 2,5 & 2,5 & 2,5 & 2,5 \\
\hline
\end{tabular}

\section{Tahapan Kegiatan}

\section{a. Persiapan Filler}

Filler dalam hal ini pasir kuarsa terlebih dahulu dibersihkan dari benda asing dengan cara dilakukan pencucian menggunakan air sampai bersih. Proses berikutnya dilakukan penjemuran pada udara terbuka hingga kadar air 3\%. Setelah kadar air mencapai 3\% selanjutnya dikeringkan dalam open pada suhu $110{ }^{\circ} \mathrm{C}$ hingga kadar air maksimum 0,5\%. Tahap berikutnya pasir kuarsa yang telah kering (kadar air maksimum 0,5\%) dilakukan pengecilan ukuran dengan cara digiling menggunakan crusher. Hasil gilingan selanjutnya dilakukan pengayakan dengan menggunakan ayakan 100 mesh. Bagian pasir kuarsa yang lolos ayakan ukuran 100 mesh untuk membuat produk rubber step sepeda motor.

\section{b. Proses Vulkanisat Karet}

1. Seluruh bahan yang digunakan untuk kegiatan penelitian ini dari setiap formula dilakukan penimbangan sesuai dengan desain rasio bahan yang terdapat pada Tabel 1. Berat bahan yang digunakan untuk seluruh pelakuan dinyatakan dalam ukuran phr.

2. Tahapan Pembuatan Kompon

Karet alam sesuai dengan berat (Tabel 1) masing-masing dilakukan mastikasi dengan cara penggilingan menggunakan alat giling open mill sampai plastis ( \pm 7 menit). Setelah karet menjadi plastis selanjutnya ditambahkan pasir kuarsa bersama dengan karbon hitam N.330 sampai semuanya menjadi homogen dengan karet. Selama dilakukan penggilingan dilakukan juga pemotongan pada setiap sisi kiri dan kanan karet pada roll mill untuk mempercepat homogenitas karbon hitan dan pasir kuarsa kedalam matriks karet. Pemotongan kompon selama penggilingan dilakukan setiap 1 sampai 2 menit untuk mempercepat homogenitas. Setelah semua karbon hitam dan pasir kuarsa homogen di dalam karet selanjutnya ditambahkan $\mathrm{ZnO}$, asam stearat secara bersamaan hingga semuanya homogen dan bercampur di dalam karet. Berikutnya secara bersama-sama juga ditambahkan 6.PPD, CBS dan TMTD, sambil terus digiling dan dilakukan juga pemotongan pada setiap sisi karet. Setelah semua bahan proses homogen dalam matriks karet, berikutnya tambahkan sulfur hingga semuanya menyatu dalam matriks karet. Pada tahapan ini menghasilkan kompon karet sebagai bahan untuk dicetak menggunakan alat cetak. Pada proses pencetakan terjadi pristiwa vulkanisasi dengan membentuk jaringan tiga dimensi 
yang disebabkan oleh belerang yang menghasilkan vulkanisat karet.

\section{c. Pengujian Vulkanisat}

Vulkanisat karet yang dihasilkan dilakukan pengujian dengan parameter untuk bantalan kaki sepeda motor sesuai persyaratan SNI 06-7032-2004.

\section{HASIL DAN PEMBAHASAN}

Hasil pengujian karakteristik untuk pematangan kompon dari 4 (empat) perlakuan diperlihatkan pada Tabel 2. Hasil pengujian sifat mekanik vulkanisat untuk parameter kekerasan pada Gambar 1, tegangan putus pada Gambar 2, dan perpanjangan putus pada Gambar 3.

Tabel 2. Hasil Tes Rheometer

\begin{tabular}{lcccc}
\hline \multirow{2}{*}{ Rheometer } & \multicolumn{4}{c}{ Perlakuan } \\
\cline { 2 - 5 } & $\mathrm{P}_{1}$ & $\mathrm{P}_{2}$ & $\mathrm{P}_{3}$ & $\mathrm{P}_{4}$ \\
\hline $\mathrm{S}_{\max }(\mathrm{kg} / \mathrm{cm})$ & 4,62 & 4,79 & 4,96 & 4,99 \\
$\mathrm{~S}_{\min }(\mathrm{kg} / \mathrm{cm})$ & 0,14 & 0,15 & 0,16 & 0,17 \\
$\Delta \mathrm{S}(\mathrm{kg} / \mathrm{cm})$ & 4,48 & 4,64 & 4,80 & 4,82 \\
$\mathrm{t}_{90}(\mathrm{~min}, \mathrm{sec})$ & 5,28 & 5,35 & 5,36 & 5,38 \\
$\mathrm{ts}_{2}(\mathrm{~min}, \mathrm{sec})$ & 4,04 & 4,05 & 4,07 & 4,09 \\
\hline
\end{tabular}

\section{Karakteristik Vulkanisasi Kompon}

Pengujian torsi maksimum $\left(S_{\max }\right)$ pada penelitian ini dilakukan untuk melihat perubahan nilai viskositas maksimum dari setiap perlakuan dan sifat stiffness vulkanisat yang telah mengalami proses vulkanisasi. Selain itu densitas ikatan silang (crosslink density) yang terjadi dapat dilihat dari hasil pengujian torsi maksimum (Markovic et al., 2009). Nilai torsi maksimum dengan semakin besar penambahan pasir kuarsa dari 60 phr hingga 75 phr (Tabel 1) dapat meningkatkan torsi maksimum (Tabel 2).

Pasir kuarsa mengandung silika yang memiliki gugus hidroksil dibagian permukannya, sehingga membentuk ikatan hidrogen intermolecular dan menghasilkan agregat yang kokoh (Ulfah et al., 2015). Data pengujian menunjukkan, torsi minimum $\left(\mathrm{S}_{\min }\right)$ untuk viskositas dari masing-masing contoh uji ada bagian yang belum matang (Tabaei et al., 2015). Peningkatan $S_{\min }$ pada
Tabel 2 berbanding lurus dengan peningkatan rasio pasir kuarsa (Tabel 1). $\mathrm{Hal}$ ini menunjukkan pengaruh peningkatan jumlah pasir kuarsa yang ditambahkan berpengaruh terhadap peningkatan viscositas kompon karet. Pada proses awal vulkanisasi ikatan silang yang membentuk vulkanisat dari kompon karet belum terjadi. peningkatan jumlah pasir kuarsa menghambat mobilitas deformasi rantai molekul karet yang membentuk nilai torsi minimum. Nilai torsi minimum dapat menggambarkan telah terjadi peningkatan luas permukaan spesifik bahan pengisi pada kompon ( $\mathrm{Li}$ et al., 2008). Dengan demikian rantai karet sebagian besar mobilitasnya terhambat. Peristiwa ini berpengaruh terhadap efek reinforcement kompon karet.

Derajat ikatan silang yang terbentuk selama pristiwa vulkanisasi dapat digambarkan oleh deta torsi $(\Delta S)$ (Markovic et al., 2010). Pasir kuarsa yang ditambahkan sebagai pengisi pada pembuatan kompon karet selama penggilingan ditujukan untuk menaikkan nilai delta torsi $(\Delta S)$. Bahan pengisi pasir kuarsa yang ditambahkan pada kompon karet dengan ukuran 100 mesh, untuk meningkatkan nilai derajat ikatan silang vulkanisat yang terbentuk. Silika sebagai bahan pengisi aktif dapat meningkatkan kepadatan ikatan silang (Ahmed et al., 2013).

Pematangan optimum ( $\left.\mathrm{t}_{90}\right)$ adalah waktu yang menyatakan pristiwa terjadinya pematangan kompon menjadi vulkanisat karet. Hasil pengujian menunjukkan, untuk perlakuan 60 phr dari penelitian ini merupakan waktu pemasakan paling singkat, jika dibandingkan perlakuan $65 \mathrm{phr}, 70 \mathrm{phr}$, dan 75 phr. Perlakuan $P_{1}$ pada penelitian ini adalah perlakuan yang paling optimal pembuatan kompon karet bantalan kaki sepeda motor. Waktu scorch ( $\left.\mathrm{ts}_{2}\right)$ dinyatakan sebagai waktu sebelum terjadinya proses vulkanisasi. Pasir kuarsa yang ditambahkan pada kompon karet saat penggilingan $60 \mathrm{phr}$ s.d $75 \mathrm{phr}$ dari hasil pengamatan terjadi peningkatan waktu scorch. Data hasil pengujian untuk waktu scorch dari 
seluruh perlakuan nilainya hampir mempunyai kesamaan. $\mathrm{Hal}$ ini menunjukkan, semua perlakuan nilainya mendekati kesamaan sehingga nilainya tidak berpengaruh nyata antar perlakuan terhadap waktu scorch. Waktu scorch dan waktu pematangan optimal menginterpretasikan kinetika vulkanisasi (Tabaei et al., 2015).

\section{Kekerasan}

Hasil pengujian parameter untuk kekerasan ditujukan sebagai ukuran yang dapat melihat resistensi bahan yang berpengaruh terhadap deformasi plastis lokal dari masing-masing perlakuan $\left(P_{1}\right.$ s.d $\left.P_{4}\right)$. Perbedaan nilai kekerasan vulkanisat yang terjadi pada Gambar 1 dapat disebabkan oleh adanya perbedaan berat bahan pengisi (pasir kuarsa) yang digunakan.

Hasil pengujian untuk kekerasan yang tertinggi dari semua perlakuan $\left(P_{1}\right.$ s.d $\mathrm{P}_{4}$ ) yaitu dari perlakuan $\mathrm{P}_{4}$ dengan nilai 58 Shore $A$, untuk kekerasan terendah dengan nilai 56 Shore A diperoleh dari perlakuan $\mathrm{P}_{1}$ (Gambar 1 ). Jumlah pasir kuarsa sebagai filler yang ditambahkan (Table 1) memberikan nilai kekerasan yang berbeda secara signifikan untuk perlakuan $\mathrm{P}_{1}$ dengan $\mathrm{P}_{4}$. Penambahan jumlah pasir kuarsa yang digunakan dari perlakuan $\mathrm{P}_{1}$ dengan $\mathrm{P}_{4}$ dapat meningkatkan nilai kekerasan dari 56 - 58 Shore A.

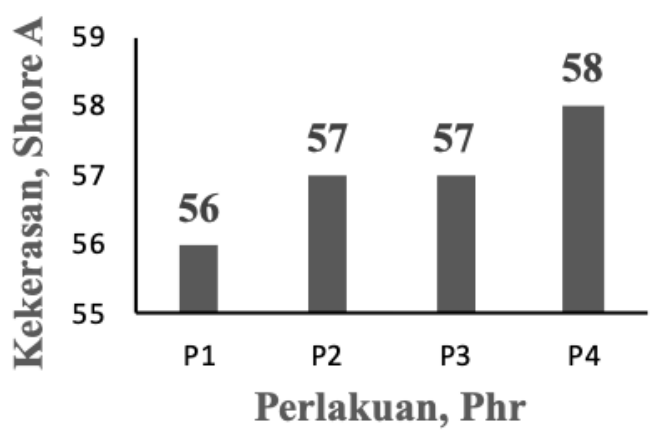

Gambar 1. Kekerasan rubber step sepeda motor.

Pada rasio pasir kuarsa $\mathrm{P}_{2}$ dan $\mathrm{P}_{3}$ nilai kekerasannya sama yaitu 57 Shore A. Menurut (Ahmed et al., 2013;
Foaad et al., 2016) penambahan silika dapat meningkatkan nilai kekerasan. Pasir kuarsa hampir disemua negara memiliki sudut ikatan yang seragam dan panjang (Ripan et al., 2018). Menurut Rattansom et al, (2009) silika sebagai bahan pengisi pada pembuatan kompon karet rasionya dua kali dari rasio karbon hitam yang digunakan. Hasil pengujian kekerasan vulkanisat untuk semua perlakuan sesuai dengan SNI 06-7032$2004(60 \pm 5$ Shore A).

\section{Tegangan Putus}

Nilai tegangan putus dari data pengujian untuk 4 (empat) sampel vulkanisat pada Gambar 2 terjadi peningkatan yang cukup signifikan untuk perlakuan $\mathrm{P}_{1}$ dengan $\mathrm{P}_{4}$. Pada perlakuan $P_{1}$ nilai tegangan putus $188 \mathrm{~kg} / \mathrm{cm}^{3}$, untuk perlakuan $\mathrm{P}_{4}$ merupakan nilai tertinggi dari semua perlakuan yaitu 195 $\mathrm{kg} / \mathrm{cm}^{2}$. Sementara untuk perlakuan $P_{1}$ s.d $\mathrm{P}_{3}$ dari data pengujian kenaikan nilai tegangan putus tidak signifikan atau terjadi secara bertahap. Peningkatan nilai tegangan putus yang terjadi berbanding lurus dengan peningkatan rasio pasir kuarsa yang ditambahkan (Gambar 2).

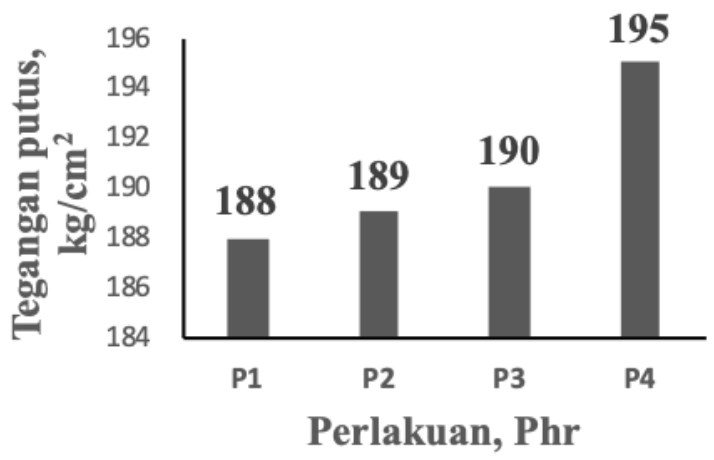

Gambar 2. Tegangan putus rubber step sepeda motor

Dengan bertambahnya jumlah pasir kuarsa pada pembuatan kompon karet nilai tegangan putus cenderung lebih tinggi atau nilainya mengalami kenaikan. Perbedaan rasio pasir kuarsa yang ditambahkan dari masing-masing perlakuan terlihat hasilnya berpengaruh terhadap perbedaan nilai tegangan putus 
dari vulkanisat yang dihasilkan. Pasir silika dengan proses benefisiasi dengan metode kimia dapat meningkatkan kualitas $\mathrm{SiO}_{2}$ hingga mencapai kemurnian tinggi yaitu $98,77 \%$ (Suratman dan Handayani, S, 2014). Silika yang terkandung dalam pasir kuarsa dapat meningkatkan ikatan atar matrik karet, sehingga menghasilkan nilai kekuatan tarik yang lebih baik (Fragiadakis et al., 2011).

Pasir kuarsa yang ditambahkan sebagai pengisi pada penelitian ini kemungkinan masih ada bahan pengotor yang tidak terlihat secara visual. Senyawa pengotor yang ada pada pasir kuarsa kemungkinan pada saat pencuciaan masih belum bersih, senyawa pengotor kemungkinan juga terikat pada butiran pasir kuarsa (Pitriani, 2010). Data hasil penelitian interaksi antara vanadium dengan nikel dan pasir kuarsa menunjukkan pada proses pencucian pasir kuarsa dapat menghilangkan pengotornya (Lesbani, 2011). Kandungan silika yang tinggi dari hasil pencucian pasir kuarsa dapat menghasilkan vulkanisat karet dengan sifat mekanik yang lebih baik. Hasil pengujian nilai tegangan putus untuk semua perlakuan masih memenuhi syarat mutu SNI 06-7032-2004 (min 100 $\mathrm{kg} / \mathrm{cm}^{2}$ ).

\section{Perpanjangan Putus}

Pengujian perpanjangan putus dilakukan untuk mempelajari pengaruh perbedaan rasio pasir kuarsa dari masing-masing perlakuan terhadap perbedaan nilai perjangan putus. Hasil pengujian perpanjangan putus sama halnya dengan hasil pengujian tegangan putus yang nilainya mempunyai trand kenaikan yang sama yaitu mengikuti peningkatan rasio pasir kuarsa yang ditambahkan (Tabel 1 dan Gambar 3).

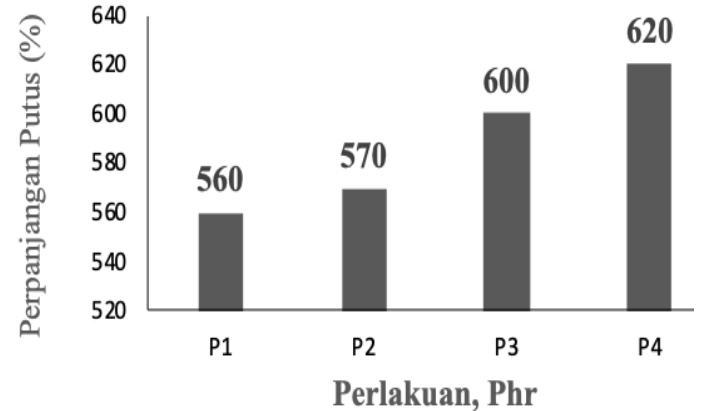

Gambar 3. Perpanjangan putus rubber step sepeda motor.

Nilai perpanjangan putus tertinggi (620\%) diperoleh dari perlakuan $\mathrm{P}_{4}$, untuk nilai perpanjangan putus terendah (560\%) dihasilkan dari perlakuan $P_{1}$. Data hasil pengujian menunjukkan, semakin besar penambahan bahan pengisi pasir kuarsa (Table 1) dapat meningkatkan nilai perpanjangan putus (Gambar 3). Hal ini dikarenakan adanya pengaruh ukuran partikel pasir kuarsa yang digunakan dengan ukuran 100 mesh, yang menyebabkan dispersi nya ke matrik polimer tidak baik, sehingga berpengaruh pada fluktuasi nilai dari perpanjangan putus dimana menimbulkan efek yang tidak menguatkan, meskipun pasir kursa mengandung senyawa $\mathrm{SiO}_{2}$ besar. Menurut Darwis et al, 2017, Penelitian tentang pemurnian silika pasir kuarsa menggunakan metode pemurnian yang menghasilkan $\mathrm{SiO}_{2} 99,9 \%$, jika jumlah dan penyebarannya tidak merata dalam matriks karet nilai perpanjangan putus yang dihasilkan mengalami perbedaan, namun nilai perpanjangan putus vulkanisat untuk semua perlakuan memenuhi syarat mutu SNI 06-70322004 ( $\min 350 \%$ ).

\section{KESIMPULAN}

Penelitian perbedaan jumlah pasir kuarsa dari perlakuan $\left(P_{1}\right.$ s.d $\left.P_{4}\right)$ pada pembuatan kompon vulkanisat karet bantalan kaki sepeda motor telah dilakukan. Pasir kuarsa yang telah dibersihkan dan dihaluskan melalui proses penggilingan hingga kehalusan 100 mesh pada penelitian dapat dimanfaatkan untuk bahan pengisi rubber step sepeda motor. Hasil 
pengujian vulkanisat untuk perlakuan $P_{1}$ merupakan formula terbaik yang memenuhi syarat mutu SNI 06-70322004 untuk rubber step sepeda motor. Pasir kuarsa 60 phr $\left(P_{1}\right)$ dengan karakteristik pematangan kompon $\mathrm{S}_{\max }=$ $4,62 \mathrm{~kg} / \mathrm{cm}, S_{\min }=0,14 \mathrm{~kg} / \mathrm{cm}, \Delta S=4,48$ $\mathrm{kg} / \mathrm{cm}, \mathrm{t}_{90}=5,28 \mathrm{~min}$ dan $\mathrm{ts}_{2}=4,04 \mathrm{~min}$, hasil uji kekerasan 57 shore $\mathrm{A}$, tegangan putus $188 \mathrm{~kg} / \mathrm{cm}^{2}$ dan perpanjangan putus $560 \%$.

\section{UCAPAN TERIMA KASIH}

Dalam kesempatan ini peneliti menyampaikan terima kasih kepada Pimpinan Baristand Industri Palembang telah memberikan fasilitas untuk riset, reviewer, editor pada Jurnal Dinamika Penelitian Industri atas koreksi, saran yang diberikan, Bapak Dr. Nasruddin., S.T., M.Si yang telah memberikan bimbingan dalam penulisan manuscript, Bapak Wahyu dan Bapak Aidil atas bantuannya pada kegiatan lapangan dan laboratorium sehingga selesainya riset ini.

\section{DAFTAR PUSTAKA}

Ahmed, K., Shaikh, S.N., Nudrat, Z.R., and Farzana, H. (2013). The Effect of Silica on The Properties of Marble Sludge Filled Hybrid Natural Rubber Composites. J. King Saud UniversityScience. 25(4): 331-339.

Bach, Q.V., Cuong, M.V., and Huong, T.V. (2019). Effects of Co-Silanized Silica on the Mechanical Properties and Thermal Characteristics of Natural Rubber/Styrene-Butadiene Rubber Blend. Silicon, doi.org/10.1007/s12633-019-00281-8.

Darwis D, Khaeroni, R and lqbal I. (2017). Natural Science. Journal of Science and Technology. 6(2).

Foaad, S., Hashim., Mohammad, H.A., Farah, J., and Hamood. (2016). Effect of Silica on the Mechanical Properties of Rubber Reclaim Composite. International Journal of ChemTech Research. 9(4): 325-333.

Fragiadakis, D., Bokobza, L., and Pissis, P. (2011). Dynamics Near The Filler Surface in Natural Rubber-Silica nanocomposites. Polymer, 52(14): 3175-3182.

Frochlich, J., W, Niedermeier, and H.D. Luginsland, (2005). The Effect of Filer Filler and Filler Elastomer Interaction on Rubber Reinforcement. Composites Part A. Applied Science and Manufacturing. 36(4): 449-460.

Hadi, Suratman., Munasir, T. (2010). Sintesis Silika Berbasis Pasir Alam Bancar Menggunakan Metode Kopresipitasi, 1-5. Retrieved from http://doi.org/10.12962/j24604682.v7i2 .902.

Ku, H., Y and Shao., A. (2011). Riview on The Tensile Properties of Natural Fiber Reinforced Polymer Composites. Composites Part B: Engineering. 42(4): 856-873.

Lesbani, A. (2011). Studi Interaksi Vanadium dan Nikel dengan Pasir Kuarsa. Jurnal Penelitian Sains. 14(4) (C).

Li, Z. H., Zhang, J., and Chen, S, J. (2008). Effect of Carbon Blacks with Various Structures on vulcanization and Reinforcement of Filled Ethylene Propylene-Diene Rubber. Express Polymer Letters, 2(10): 695-704.

Liu, H.P.L., Yuanfang, L., Demin, J., and Weiwen, F. (2007). Novel Blocked Mercaptosilane (3-Propionylthio-1Propyltrimethoxylsilane) for Natural Rubber/Silica Composite Reinforcement in Various Curing Systems. e-Polymers, 104: 1-9. Retrieved from doi.org/10.1515/epoly.2008.8.1.1190.

Markovic, G., Radovanovic, B., MarinovicCincovic, M., and Budinski-Simendic, J. (2009). The Effect of Accelerators on Curing Characteristics and Properties of Natural Rubber/Chlorosulphonated Polyethylene Rubber Blend. Materials and Manufacturing Processes. 24(1011): 1224-1228.

Markovic, G., Samarzija-Jovanovic, S., Jovanovic, V., and Marinovic-Cincovic, M. (2010). Thermal Stability of CR/CSM Rubber Blends Filled with Nano- and Micro-Silica Particles. Journal of Thermal Analysis and Calorimetry. 100(3): 881-888.

Peng, H., Liu. L., Luo, Y., Hong, H., and Jia, D. (2009). Synthesis and characterization of 3-benzothiazolthio1-propyltriethoxylsilane and Its Reinforcement for Styrene-butadiene 
Rubber/Silica Composites. Journal of Applied Polymer Science. 112: 19671973. DOI: 10.1002/app.29634.

Pitriani, P. (2010). Sintesis dan Aplikasi Kitosan dari Cangkang Rajungan (Portunus pelagicus) sebagai Penyerap Ion Besi (Fe) dan Ion Mangan (Mn) untuk Pemurnia Natrium Silikat. (Skripsi). Jakarta: Universitas Islam Negeri Syarif Hidayatullah Jakarta.

Qian, M., Weimin, H., Jinfeng, W., Xiaofeng, W., Weiping, L., and Yanchao, Z. (2019). Surface Treatment Effects on the Mechanical Properties of Silica Carbon Black Reinforced Natural Rubber/Butadiene Rubber Composites. Polymers. (11): 1763; doi:10.3390/polym11111763.

Rachman, A., Frank, E., dan Pius, S. (2012). Karakterisasi Pasir Silika Cibadak Sukabumi sebagai Bahan Baku Pembuatan Ramming Mix Silica. Majalah Metalurgi. 27(3): 263-272.

Rahmaniar. (2015). Karakterisasi Kompon Karet dengan Penambahan Ekstrak Kayu Secang, Silika Pasir Kuarsa dan Kalsium Karbonat Kulit Kerang (Disertasi). Palembang: Universitas Sriwijaya.

Rattanasom, N., Prasertsri, S., Ruangritnumchai, T. (2009). Comparison of The Mechanical Properties at Similar Hardness Level of Natural Rubber Filled with Various Reinforcing - Fillers. Journal of Polymer Testing. 28(1): 8-12. Retrieved from http://doi.org/10.1016/j.polymertesting. 2008.08.004.

Ripan, K., Biswas., Prosenjit, K., Smita, M., Anoop, K. Mukhopadhyay, Jiten, G., and Muraleedharan. K. (2018). Study of Short Range Structure of Amorphous Silica from PDF using Ag Radiation in Laboratory XRD System, RAMAN and NEXAFS. J. NonCrystalline Solids. 488: 1-9. doi.org/10.1016/j.jnoncrysol.2018.02.0 37.

Suratman dan Handayani, S, (2014). Benefisiasi Pasir Silika Sambiroto dengan Pelindian Secara Kimia dan Biologi. Indoneslan MInIng Journal. 17(3): 134-143.

Tabaei, T. A., Bagheri, R., and Hesami, M. (2015). Comparison of Cure Characteristics and Mechanical Properties of Nano and Micro SilicaFilled CSM Elastomer. Journal of Applied Polymer Science. 132(42): 42668(1-11).

Thongsang, S., and Sombatsompop, N. (2005). Effect of Filler Surface Treatment on Properties of Fly Ash/Nr Blends. ANTEC. 3278-3282.

Ukhtiyani, I, Darwis D Dan lqbal (2017). Purifikasi dan Karakterisasi Silika (SiO2) Berbasis Pasir Kuarsa dari Desa Pasir Putih Kecamatan Pamona Selatan Kabupaten Poso. Journal of Science And Technology. 6(3): 270275.

Ulfah, L, M., Fidyaningsih, R., Rahayu, S., Fitriani, D, A., Saputra, D, A., Winarto, D, A., and Wisojodharmo, L, A. (2015). Influence of Carbon Black and Silica Filler on the Rheological and Mechanical Properties of Natural Rubber Compound. Procedia Chemistry. 16. 258-264.

Yang, S.Y., Liu, L., Jia, Z.X., Fu, W.W., Jia, D.M., and Luo, Y.F. (2014). Study on The Structure-properties Relationship of Natural Rubber/SiO2 Composites Modified by a Novel Multi-functional rubber agent. eXPRESS Polymer Letters. 8(6): 425-435.

Zafarmehrabian, R, Gangali, S.T, Ghoreishy, M. H. R. and Davallu, M. (2012). The Effects of Silica/Carbon Black Ratio on The Dynamic Properties of The Tread Compounds in Truck Tires. E-Journal of Chemistry. 9(3): 1102-1112.

Zhong, B., Zhixin, J., Yuanfang, L., and Demin, J. (2015). Surface modification of Silica with N-cyclohexyl-2benzothiazole sulfenamide for Styrene-butadiene Rubber Composites with Dramatically Improved Mechanical Property. Materials Letters. 145: 41-43. 